\title{
Elaboration, Electrochemical Investigation and Morphological Study of the Coating Behavior of a New Polymeric Polyepoxide Architecture: Crosslinked and Hybrid Decaglycidyl of Phosphorus Penta Methylene Dianiline on E24 Carbon Steel in 3.5\% NaCl
}

\author{
Rachid Hssissou $^{a, *}$, Bouchra Benzidia ${ }^{b}$, Najat Hajjaji ${ }^{b}$ and Ahmed Elharfi ${ }^{a}$ \\ ${ }^{a}$ Laboratory of Agroressources, Polymers and Process Engineering (LAPPE), Team of Organic \\ Chemistry and Polymer (TOCP), Department of Chemistry, Faculty of Sciences, \\ Ibn Tofail University, P.O. Box 133, 14000, Kénitra, Morocco \\ ${ }^{b}$ Laboratory of Materials, Electrochemistry and Environment, Team of Corrosion, Protection \\ and Environment, Department of Chemistry, Faculty of Sciences, \\ Ibn Tofail University, P.O. Box 133, 14000, Kénitra, Morocco
}

Received July 20, 2017; accepted, December 28, 2017

\begin{abstract}
We developed and applied in our work a new polyepoxide polymer, decaglycidyl phosphorus penta methylene dianiline, to study its coating behavior in a marine environment. Then, we tested the new crosslinked and formulated macromolecular binder (DGPMDAP), which is used as an anticorrosive coating on E24 carbon steel, in $3.5 \% \mathrm{NaCl}$. So as to evaluate and examine the DGPMDAP coating performance in the field of E24 carbon steel corrosion, we applied the different $E_{1}$ (DGPMDAP/MDA) and $\mathrm{E}_{2}$ (DGPMDAP/MDA/PN) formulations on the metal substrate. The stationary and transient electrochemical studies are very interesting; and, in order to confirm the obtained results, we dispersed the charge of the natural phosphate that was incorporated in the $\mathrm{E}_{2}$ (DGPMDAP/MDA/PN) macromolecular matrix, through the use of a polarizing optical microscope.
\end{abstract}

Keywords: DGPMDAP, architecture, coating, crosslinking, formulation, carbon steel, and electrochemical studies.

\section{Introduction}

Polyepoxide polymeric architectures are very important thermosetting technological macromolecular matrices [1-3], since they have varied uses in industry, thanks to their numerous viscosimetric and rheological properties [4-6], such as aeronautical and spatial construction [7-9]. Corrosion inhibition [10] by the protection and coating of metallic objects [11] with inhibitors is important in the field of heritage conservation, due to their ease of implementation, according to their microscopic and macroscopic properties. The most common method

\footnotetext{
* Corresponding author. E-mail address: r.hsissou@gmail.com
} 
nowadays used to protect the materials against corrosion is to apply organic polymer films [12-13].

The synthesis and formulation of a new polyepoxide architecture were done, due to its good physicochemical properties as a coating for E24 carbon steel in marine environments. We tested the decaglycidyl polymer of phosphorus pentamethylene dianiline (DGPMDAP), crosslinked and formulated by natural phosphates, among the different coating types that can play an important role in the prevention of corrosion oxidation and heritage degradation [14-15]. This is due to its good adhesion, strong acid/alkali resistance and high cross-link density, according to its macromolecular structure [16-17].

\section{Materials and methods}

\section{Used materials}

Polyepoxide decaglycidyl of phosphorus penta-methylene dianiline (DGPMDAP) We used a new polyepoxide polymer in this work: decaglycidyl of phosphorus penta methylene dianiline (DGPMDAP), which structure is shown in Fig. 1, (methylene dianiline (MDA), natural phosphate and 3.5\% $\mathrm{NaCl}$ ). The latter products have been marketed by Aldrich Chemical Co.

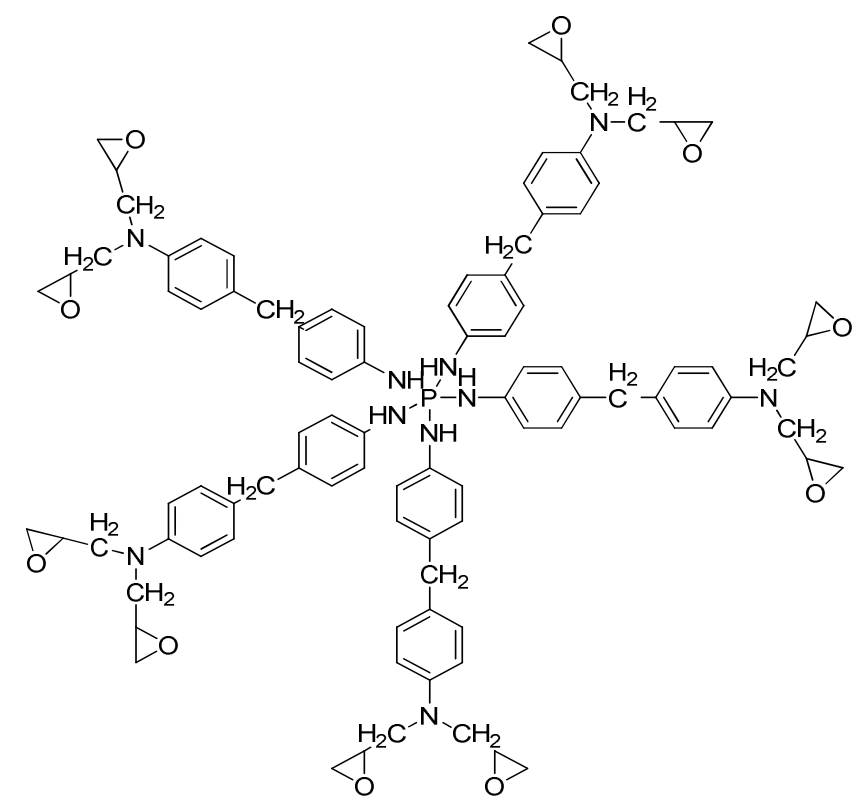

Figure 1. Semi-developed structure of decaglycidyl of phosphorus penta methylene dianiline (DGPMDAP).

\section{Crosslinking of decaglycidyl polyepoxide of phosphorus penta methylene dianiline using methylene dianiline}

The polyepoxide macromolecular polymeric architectures can be transformed into thermosetting materials, through many chemical compounds that act as a curing agent during processing. Among the hardeners of polyepoxide systems there are two major classes: acid anhydrides and amines. The latter remain good hardeners, depending on their chemical structure. The aromatic compounds provide very good thermal stability and mechanical properties to the polymer 
[18], and are often used for high-tech applications. The hardener used in this study is methylene dianiline. The crosslinking reaction of the new synthesized multifunctional polymer (DGPMDAP), in the presence of methylene dianiline (MDA) as a hardener, was under the temperature effect, following the polycondensation reaction. This leads to the three-dimensional structure shown in Fig. 2.

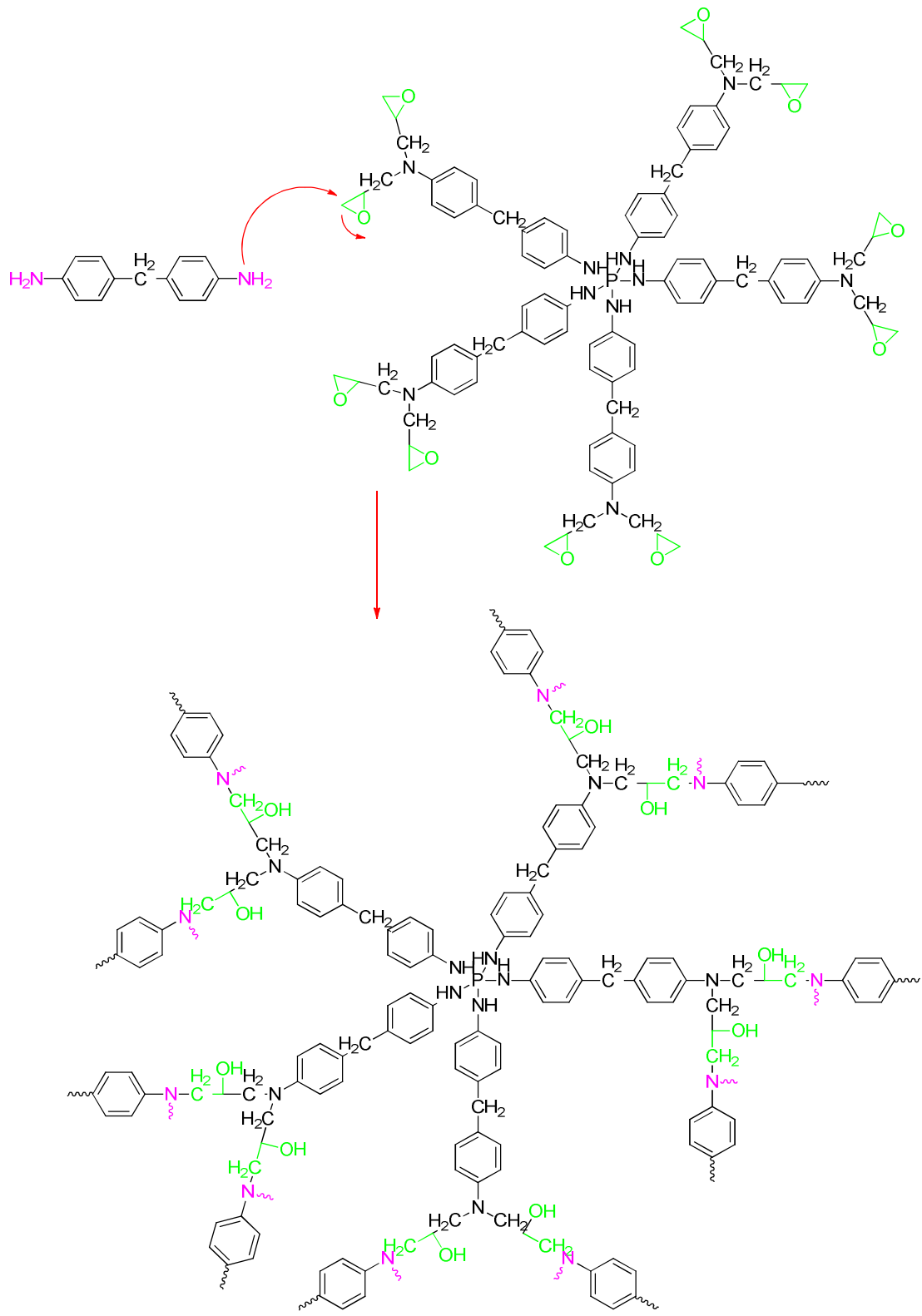

Figure 2. Scheme of decaglycidyl of penta-methylene dianiline of phosphorus crosslinked with methylene dianiline.

Formulation of decaglycidyl polyepoxide of phosphorus penta methylene dianiline in the presence of natural phosphate

Fig. 3 shows the composite photos (DGPMDAP/MDA/PN) crosslinked with methylene dianiline, and formulated by natural phosphate used as filler. 


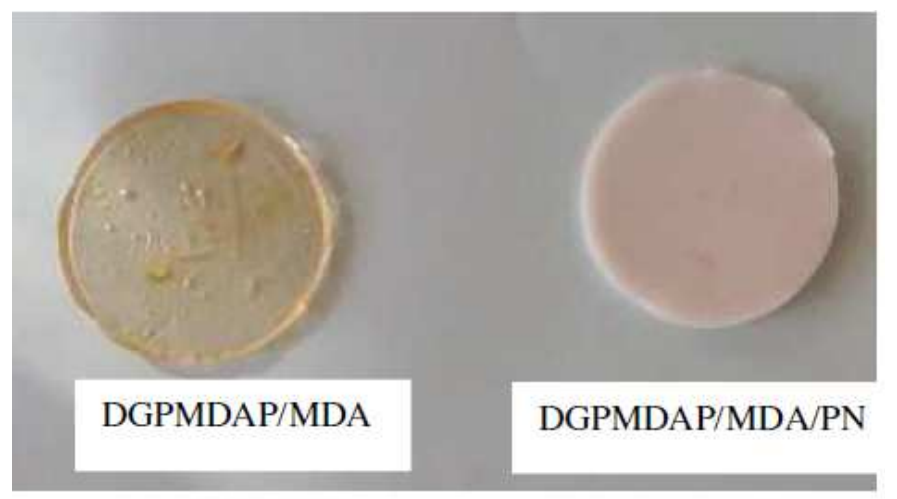

Figure 3. Photographs of the crosslinked composite formulated in the natural phosphate presence.

\section{Used methods}

\section{Electrochemical cell}

The electrochemical cell had three electrodes: a platinum counter-electrode, a saturated calomel reference electrode (SCE) and a rectangular E24 carbon steel working electrode. The surface of contact with the corrosive solution was $1 \mathrm{~cm}^{2}$. The working electrode was polished before each test with abrasive paper of 600 , 1200 and 1500 grades.

These three electrodes were immersed in a $100 \mathrm{~mL}$ container, in which orifices of well-designed diameters and spacing were provided, enabling the three electrodes introduction. This also made possible to receive the systems for agitation, temperature control, aeration and deaeration.

\section{Polarizing optical microscope}

The optical polarizing microscope is composed of a lens optical system, in order to obtain an enlarged image of the sample. The latter is an optical instrument equipped with an object and an eyepiece, which enables to enlarge the image of an object of small dimensions, and to separate its details, so that it can be observed by the human eye.

\section{Ratio calculation method}

In order to obtain optimum properties, it was desirable to make the prepolymer and the curing agent react in approximately stoichiometric amounts [7], after having cured the multifunctional polyepoxide macromolecular matrix in the hardener presence.

The epoxy equivalent weight (EEW) was calculated by:

$$
\mathrm{EEW}=\frac{\mathrm{Mw}(\mathrm{DGPMDAP})}{f}
$$

where $\mathrm{f}$ is the functionality of the synthesized epoxy resin.

$$
\begin{aligned}
& \mathrm{EEW}=\quad \frac{1576}{10} \\
& \mathrm{EEW}=\quad 157.6 \mathrm{~g} / \mathrm{eq}
\end{aligned}
$$


The amine hydrogen equivalent weight (AHEW) was calculated by:

$$
\begin{aligned}
& \text { AHEW }=\frac{\text { Mw (MDA) }}{f} \\
& \text { AEEW }=\quad \frac{198}{4}
\end{aligned}
$$

$$
\mathrm{AHEW}=49.5 \mathrm{~g} / \mathrm{eq}
$$

The ratio by weight of the hardener, with respect to the epoxy resin, is most commonly calculated by PHR (Parts per Hundred of Resin):

$$
\begin{aligned}
& \mathrm{PHR}=(\text { Amine })=\frac{\text { AHEW }}{\mathrm{EEW}} \times 100 \\
& \mathrm{PHR}=(\text { Amine })=\frac{49.5}{157.6} \times 100 \\
& \mathrm{PHR}=(\text { Amine })=31 \mathrm{~g} / \mathrm{eq}
\end{aligned}
$$

Therefore, $31 \mathrm{~g}$ of methylene dianiline per $100 \mathrm{~g}$ of DGPMDAP will have to be reacted, in order to achieve the optimum properties, when we cure the prepolymer with methylene dianiline.

The natural phosphate ratio to the weight was calculated by the following equation:

$$
\mathrm{Y} \%=\frac{\mathrm{x}}{\operatorname{resin}+\mathrm{MDA}+\mathrm{x}}
$$

where $\mathrm{x}$ is the quantity of the DGPMDAP resin and $\mathrm{y}$ is the amount of the natural phosphate charge.

Fig. 3 shows the composite photos (DGPMDAP/MDA/PN).

Method for the E24 carbon steel coating by decaglycidyl of crosslinked and formulated phosphorus penta methylene dianiline

The surface plate was polished with abrasive paper of increasingly fine granulometry $(600,1200$ and 1500) before each test, in order to obtain reliable and reproducible results. The used experimental protocol was as follows:

Formulation 1 (DGPMDAP/MDA): we mixed $1 \mathrm{~g}$ of DGPMDAP with $0.31 \mathrm{~g}$ of MDA as a hardener, and then we stirred the mixture for about $30 \mathrm{~min}$, to give a single fluid phase. The formulation was applied to the E24 carbon steel with a film-producing rod. This coated plate was placed in the oven at $70{ }^{\circ} \mathrm{C}$ for 24 hours, to crosslink the polymer which was deposited on the substrate.

$>\quad$ Formulation 2 (DGPMDAP/MDA/PN): we followed the same previous protocol (formulation 1 ) with the addition of $5 \%$ of natural phosphate as filler. 


\section{Results and discussions}

\section{Polarization curves}

The stationary measurements were carried out in potentiodynamic mode, through the use of a SP-200 "Biologic Science Instruments" potentiometer/galvanostat. The working electrode was previously immersed at the free corrosion potential for $30 \mathrm{~min}$. The scanning speed was $1 \mathrm{mV} / \mathrm{s}$, and the determination of the electrochemical parameters ( $i_{\text {corr }}, E_{\text {corr }}, \beta a$ and $\beta_{c}$ ) from the polarization curves was done using a non-linear regression by the Ec-Lab software. Thus, the coating efficiency was calculated from the following formula:

$$
\eta \%=\left(\frac{i_{c o r r}^{0}-i_{c o r r}}{i_{c o r r}^{0}}\right) \times 100
$$

where $\mathrm{i}_{\text {corr }}$ and $\mathrm{i}_{\text {corr }}$ are, respectively, the corrosion current densities $\left(\mathrm{A} \cdot \mathrm{cm}^{-2}\right)$, without and with the coating polymer, with different formulations.

$\beta_{\mathrm{a}}$ and $\beta_{\mathrm{c}}$ are, respectively, the Tafel constant of the anodic and cathodic reactions $\left(\mathrm{V}^{-1}\right)$. These constants are related to the Tafel $\beta\left(\mathrm{V} \mathrm{dec}{ }^{-1}\right)$ slope by the form on the logarithmic scale given by:

$$
\beta=\frac{\ln (10)}{b}=\frac{2.303}{b}
$$

The potentiodynamic polarization curves, which describe the protective effect of the $\left(\mathrm{E}_{0}\right), \mathrm{E}_{1}(\mathrm{DGPMDAP} / \mathrm{MDA})$ and $\mathrm{E}_{2}$ (DGPMDAP/MDA/PN) formulations on E24 carbon steel in a marine environment, are presented in Fig. 4.

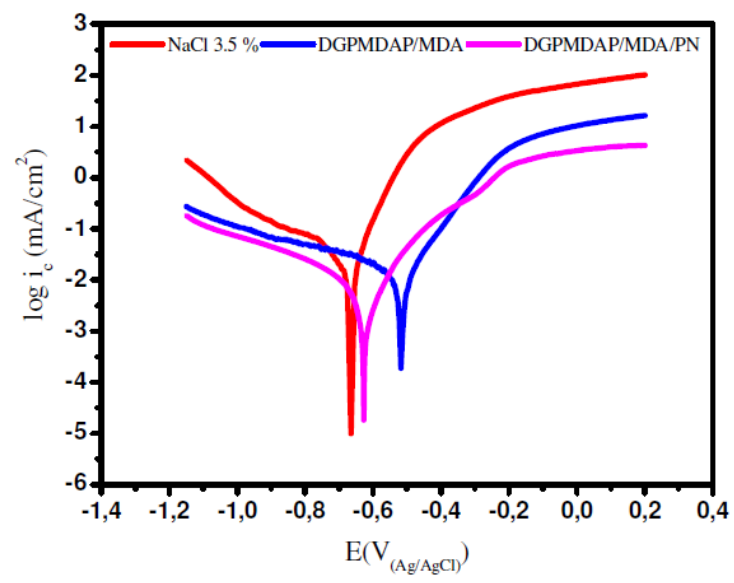

Figure 4. Polarization curves of $\mathrm{E} 24$ carbon steel in $3.5 \% \mathrm{NaCl}$, in the presence of the matrices $\left(E_{0}, E_{1}\right.$ and $\left.E_{2}\right)$, after 30 min immersion, at $298 \mathrm{~K}$.

The electrochemical parameters of the $\mathrm{E}_{0}, \mathrm{E}_{1}$ (DGPMDAP/MDA) and $\mathrm{E}_{2}$ (DGPMDAP/MDA/PN) coating matrices are summarized in Table 1.

In the control $\mathrm{E}_{0}$ matrix, which does not have the substrate coating, the $\mathrm{C}^{-}$and hydroxyl $\mathrm{OH}^{-}$chloride anions coming from the corrosive medium directly attack the substrate, inducing direct corrosion. The results in Table 1 show that the addition of the $\mathrm{E}_{1}$ and $\mathrm{E}_{2}$ formulations to the corrosive solution leads to a change in the corrosion potential ( $\mathrm{E}_{\mathrm{corr}}$ ), in the cathodic and anodic domains towards the positive values, and to a marked decrease in the current density. 
Table 1. Various electrochemical parameters taken from the polarization curves.

\begin{tabular}{lccccc}
\hline \multicolumn{1}{c}{ Protective matrices } & $\begin{array}{c}-\mathbf{E}_{\mathbf{c o r r}} \\
(\mathbf{m V} / \mathbf{A g} / \mathbf{A g C l})\end{array}$ & $\begin{array}{c}\mathbf{i}_{\text {corr }} \\
\left(\boldsymbol{\mu} \mathbf{A} / \mathbf{c m}^{2}\right)\end{array}$ & $\begin{array}{c}\boldsymbol{\beta c} \\
(\mathbf{m V} / \mathbf{d e c})\end{array}$ & $\begin{array}{c}\boldsymbol{\beta a} \\
(\mathbf{m V} / \mathbf{d e c})\end{array}$ & $\begin{array}{c}\mathbf{\eta} \\
(\mathbf{\%})\end{array}$ \\
\hline NaCl 3.5 \% & 665 & 36 & 405 & 88 & - \\
DGPMDAP/MDA & 624 & 5 & 242 & 136 & 86 \\
DGPMDAP/MDA/PN & 514 & 3 & 71 & 53 & 91 \\
\hline
\end{tabular}

In this part of our work, we studied the protection mechanism of E24 carbon steel by the following new matrices $\left(E_{1}\right.$ and $\left.E_{2}\right)$, mainly composed of the new polymeric polyepoxide architecture (DGPMDAP), the hardener (MDA) and the natural phosphate (PN) charge. The results interpretation, according to the constitution of the multifunctional macromolecular matrix, is given as follows.

Figs. 5 and 6 show, respectively, the protection mechanism of E24 carbon steel by the $\mathrm{E}_{1}$ (DGPMDAP/MDA) and $\mathrm{E}_{2}$ (DGPMDAP/MDA/PN) formulations, with and without natural phosphate.

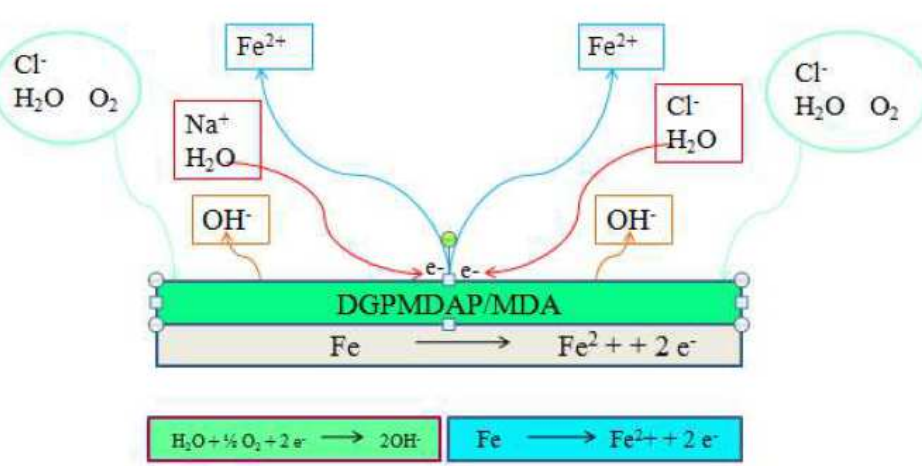

Figure 5. Mechanism of the $\mathrm{E}_{1}$ protective matrix (DGPMDAP/MDA) amid the metal substrate and the film, after immersion in $3.5 \% \mathrm{NaCl}$.

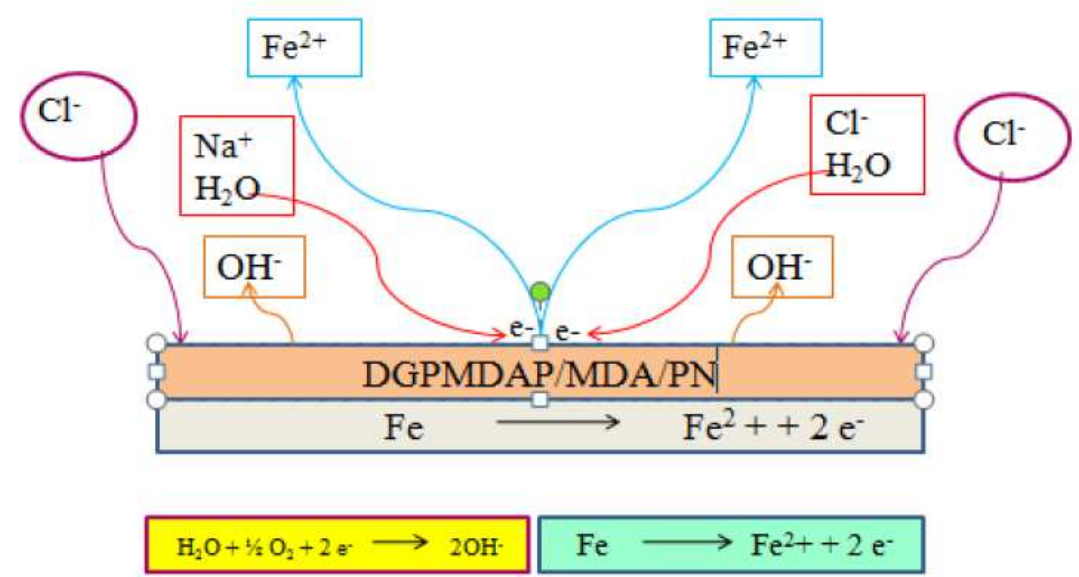

Figure 6. Mechanism of the $\mathrm{E}_{2}$ protective matrix (DGPMDAP/MDA/PN) amid the metal substrate and the film, after immersion in $3.5 \% \mathrm{NaCl}$.

In the $\mathrm{E}_{1}$ protective matrix (DGPMDAP/MDA) presence on the metal substrate (E24 carbon steel) immersed in the sorptive solution for $30 \mathrm{~min}$, we observed a relatively large diffusion of the chloride and hydroxyl ions through the protection film, which could present micropores by inducing primary corrosion translated 
by $\mathrm{i}_{\text {corr }}=5 \mu \mathrm{A} / \mathrm{cm}^{2}$, and an efficiency of $\rceil \%=86 \%$. This is explained by the acceleration of the cathodic and anodic metal dissolution [19]. The protection mechanism of the $\mathrm{E}_{1}$ matrix is shown in Fig. 5.

Furthermore, through the E2 protective matrix (DGPMDAP/MDA/PN) on the E24 carbon steel immersed in the sorptive solution for $30 \mathrm{~min}$, in the presence of natural phosphate as filler, we found that the corrosive species (chloride ions $\mathrm{Cl}^{-}$ and hydroxyl $\mathrm{OH}^{-}$) diffusion is slowed down due to the layer formed by natural phosphate [20-21]. This indicates the decrease in the dissolution rate of the substrate coated by the E2 formulation. Thus, the corrosion electrochemical parameters are $\mathrm{i}_{\text {corr }}=3 \mu \mathrm{A} / \mathrm{cm}^{2}$, and the coating efficiency reaches a maximum value of $\eta=91 \%$. The $E_{2}$ matrix protection mechanism is shown in Fig. 6 .

The corrosion potential globally moves towards the anode direction, after the $\mathrm{E}_{1}$ (DGPMDAP/MDA) and $\mathrm{E}_{2}$ (DGPMDAP/MDA/PN) protective matrices addition, and the addition of $5 \%$ of natural phosphate is accompanied by a marked decrease in the corrosion current, in both the cathodic and anodic domains. This allowed us to conclude that the natural phosphate addition to the $\mathrm{E}_{2}$ protective matrix makes it well cured and to act as a mixed inhibitor.

\section{Electrochemical impedance}

The electrochemical impedance spectroscopy measurements were carried out by using the same apparatus with a signal amplitude of $10 \mathrm{mV}$, and the explored frequency range varied from $100 \mathrm{kHz}$ to $10 \mathrm{mHz}$. The results were then analyzed by using an equivalent electrical circuit, and the Bouckamp simulation program [22]. The effectiveness of the coating protection was calculated by the following equation:

$$
\eta \%=\left(\frac{R_{p}-R_{p}^{0}}{R_{p}}\right) \times 100
$$

where $\mathrm{R}_{\mathrm{p}}^{\mathrm{o}}$ and $\mathrm{R}_{\mathrm{p}}$ are, respectively, the polarization resistance in the absence and presence of the coating polymer with different formulations.

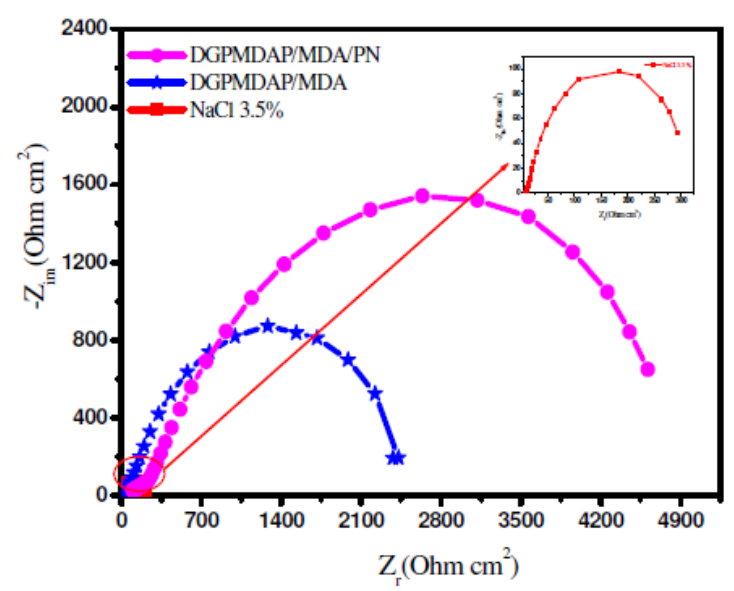

Figure 7. Open-circuit electrochemical impedance diagrams after $30 \mathrm{~min}$ of immersion for $\mathrm{E} 24$ carbon steel in $3.5 \% \mathrm{NaCl}$, in the matrices $\left(\mathrm{E}_{0}, \mathrm{E}_{1}\right.$ and $\left.\mathrm{E}_{2}\right)$ presence, at $298 \mathrm{~K}$.

The results of the electrochemical impedance spectroscopy are presented in the form of Nyquist diagrams. In order to study the coating behavior mechanism in 
detail, we carried out the impedance diagrams of the E24 carbon steel immersed in the $\mathrm{NaCl} 3.5 \%$ corrosive solution for $30 \mathrm{~min}$, with respect to the assembly of the protective matrices $\left(\mathrm{E}_{0}, \mathrm{E}_{1}\right.$ and $\left.\mathrm{E}_{2}\right)$. The latter are presented in Fig. 7, which confirms the results obtained by the potentiodynamic polarization curves.

The analysis of the different obtained results from the protective matrices $\left(\mathrm{E}_{0}, \mathrm{E}_{1}\right.$ and $E_{2}$ ) shows, respectively, that the latter are formed by a high-frequency capacitive loop attributed to the film effect, which is due to the diffusion phenomenon. On the other hand, the more the semi-circle diameter increases, the better is the protective film corrosion resistance [22].

The latter depends on the $\mathrm{E}_{1}$ and $\mathrm{E}_{2}$ coating formulations, and increases with the presence of the natural phosphate charge. This indicates that the coated substrate impedance increases with the formulations, which also increases the coating behavior effectiveness. These results confirm those obtained by the stationary method.

However, the $E_{1}$ and $E_{2}$ formulations addition improves the $R_{t c}$ values, and decreases the $\mathrm{C}_{\mathrm{dt}}$ values, because these observations clearly point out that: the E24 carbon steel corrosion in $3.5 \% \mathrm{NaCl}$ is controlled by a charge transfer process; and that the coating behavior occurs through the adsorption of the new polyepoxide DGPMDAP polymeric architecture onto the E24 carbon steel surface. The decrease in the $\mathrm{C}_{\mathrm{dt}}$ values may result from a decrease in the local dielectric constant, and/or an increase in the current density. The electrical double layer thickness suggests that the DGPMDAP macromolecular matrix functions by adsorption onto the metal solution substrate interface [23]. The effectiveness of a compound as a corrosion coating primarily depends on both the size and active centers of the DGPMDAP compound. The DGPMDAP coating improved performance can be attributed to the epoxide group's structure, and to the larger size of the DGPMDAP macromolecular matrix. Indeed, the larger semi-circle in the Nyquist diagram of the $E_{2}$ coating system indicates, more precisely, the corrosion resistance. This can be explained by the natural phosphate presence, responsible for the higher corrosion resistance. Therefore, we conclude from these results that the coating film polarization resistance values for the $E_{0}, E_{1}$ and $E_{2}$ protective matrices confirm the results of the parameters from the potentiodynamic polarization curves.

Figs. 8 and 9, respectively, show the phase angle and Bode diagrams of the E24 carbon steel coating behavior in a marine environment, which confirm the electrochemical impedance spectroscopy study. The diagrams plots of different $\mathrm{E}_{0}, \mathrm{E}_{1}$ and $\mathrm{E}_{2}$ formulations are illustrated in the figures below.

Fig. 8 shows the increase in the phase angle, according to the frequency, with different coating formulations. This increase in the phase angles confirms a higher protection by stronger coating formulations $\left(\mathrm{E}_{0}, \mathrm{E}_{1}\right.$ and $\left.\mathrm{E}_{2}\right)$; also, from this diagram, we have noticed that there are three frequency domains: low frequencies, intermediate frequencies and high frequencies. The phase angle values are approximately equal to zero at high frequencies, which indicates that the electrode behavior corresponds to the solution resistance [24]. For the intermediate frequencies, the phase angle is close to $60^{\circ}$, and there is a linear 
relation between $\log |\mathrm{Z}|$ according to $\log$ (f), with a slope close to -1 , which indicates the coating capacitive behavior at intermediate frequencies.

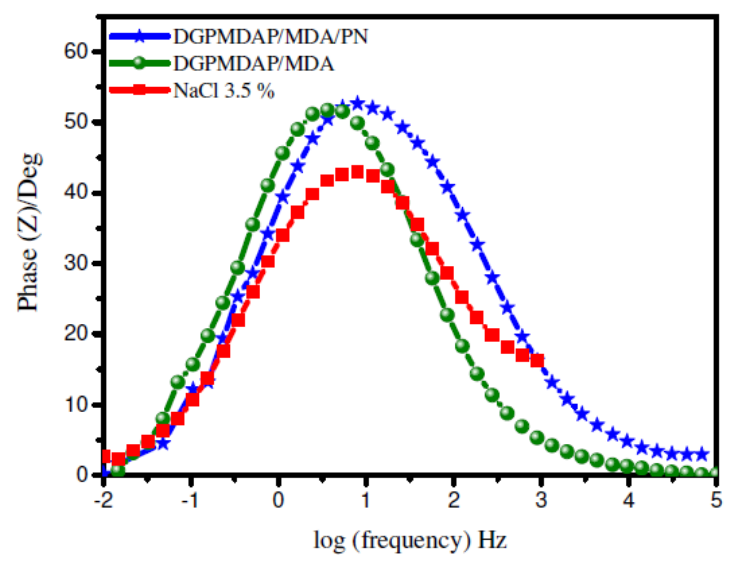

Figure 8. DGPMDAP phase angle diagrams in $3.5 \% \mathrm{NaCl}$, after $30 \mathrm{~min}$ immersion with various formulations $\left(\mathrm{E}_{0}, \mathrm{E}_{1}\right.$ and $\left.\mathrm{E}_{2}\right)$, at $298 \mathrm{~K}$.

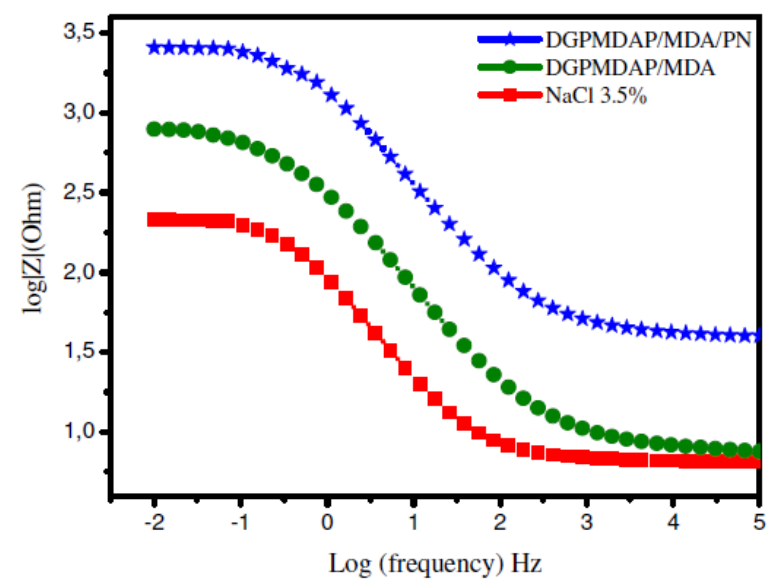

Figure 9. Bode patterns of DGPMDAP in 3.5\% $\mathrm{NaCl}$, after $30 \mathrm{~min}$ immersion with different formulations $\left(\mathrm{E}_{0}, \mathrm{E}_{1}\right.$ and $\left.\mathrm{E}_{2}\right)$, at $298 \mathrm{~K}$.

For low frequencies, the increase in the impedance absolute values (Fig. 9) confirms the greatest protection of E24 carbon steel by the different coating formulations.

In the literature, a capacitor behavior would be ideal if the slope value reached -1 , and a phase angle value reached $90^{\circ}$. The phase angle values were calculated from the phase curves $(\mathrm{Z})$, according to $\log$ (frequency). These $\alpha$ values range from -0.60 to -0.80 for the various coating formulations, which is related to the non-ideal structure of the metal/solution interface. These results confirm that of the electrochemical impedance spectroscopy.

According to the presented curve shapes, the Bode and Nyquist diagrams show a capacitive behavior at the interface, and the existence of an equivalent electrical circuit (Fig. 10), which is due to the interpretation of the information on the behavior properties of the metal surface coating or corrosion. This circuit is composed of: electrolyte resistance $\left(\mathrm{R}_{\mathrm{S}}\right)$, coating film capacity $\left(\mathrm{C}_{\mathrm{f}}\right)$, coating film resistance $\left(R_{p}\right)$, load transfer resistor $\left(R_{c t}\right)$ and double layer capacity $\left(C_{d l}\right)$. 


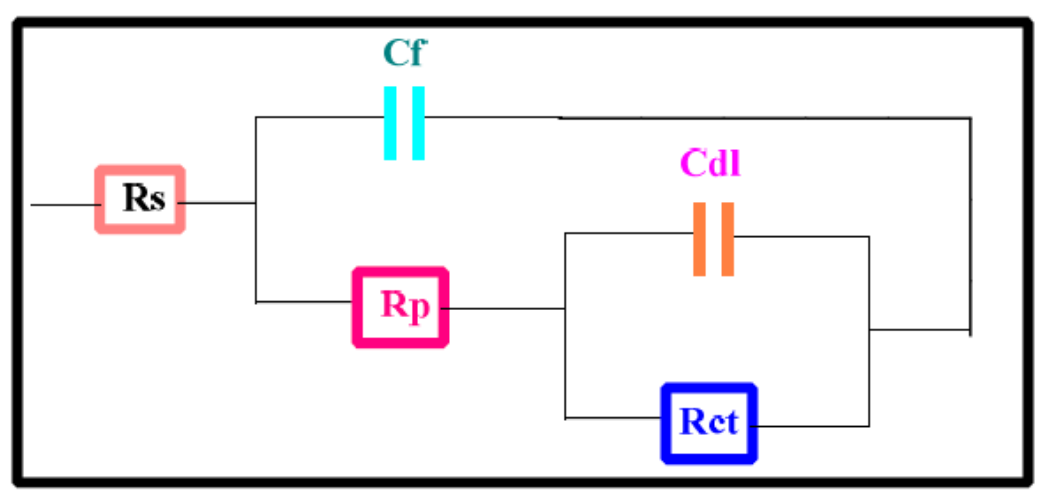

Figure 10. Equivalent electrical circuit of the impedance diagrams obtained in the presence of different formulations on E24 carbon steel, in $3.5 \% \mathrm{NaCl}$.

The electrochemical impedance and corrosion inhibition efficiency values resulting from each protection matrix $\left(\mathrm{E}_{0}, \mathrm{E}_{1}\right.$ and $\left.\mathrm{E}_{2}\right)$ are summarized in Table 2.

Table 2. Various electrochemical parameters taken from the impedance diagrams.

\begin{tabular}{ccccccc}
\hline $\begin{array}{c}\text { Protective } \\
\text { matrices }\left(\mathbf{E}_{\mathbf{i}}\right)\end{array}$ & $\begin{array}{c}\mathbf{R s} \\
\left(\mathbf{\Omega . c m}{ }^{2}\right)\end{array}$ & $\begin{array}{c}\mathbf{R}_{\mathbf{c t}} \\
\left(\mathbf{\Omega . c m}^{2}\right)\end{array}$ & $\begin{array}{c}\mathbf{C}_{\mathbf{f}} \\
\left(\boldsymbol{\mu} \mathbf{F} / \mathbf{c m}^{2}\right)\end{array}$ & $\begin{array}{c}\mathbf{C}_{\mathbf{d l}} \\
\left(\boldsymbol{\mu} \mathbf{F} / \mathbf{c m}^{2}\right)\end{array}$ & $\begin{array}{c}\mathbf{R}_{\mathbf{p}} \\
\left(\mathbf{\Omega . c m}^{2}\right)\end{array}$ & $\begin{array}{c}\mathbf{\eta} \\
(\mathbf{\%})\end{array}$ \\
$\mathrm{E}_{0}$ & 6.55 & 0.84 & 127 & 2108 & 223 & - \\
$\mathrm{E}_{1}$ & 16.58 & 39 & 2.22 & 141 & 2714 & 92 \\
$\mathrm{E}_{2}$ & 87 & 102 & 0.18 & 79 & 5552 & 95 \\
\hline
\end{tabular}

\section{Optic polarizer microscope}

We showed in this part of our work the dispersion of natural phosphate charge immersed in the $E_{2}$ macromolecular matrix (DGPMDAP/MDA/PN) on the E24 carbon steel surface, using a polarizing optical microscope to confirm the previously obtained results. The surface results obtained from the different samples $\left(E_{0}, E_{1}\right.$ and $\left.E_{2}\right)$ of the standard prepared substrate, crosslinked and formulated with the natural phosphate charge, are shown in Fig. 11.

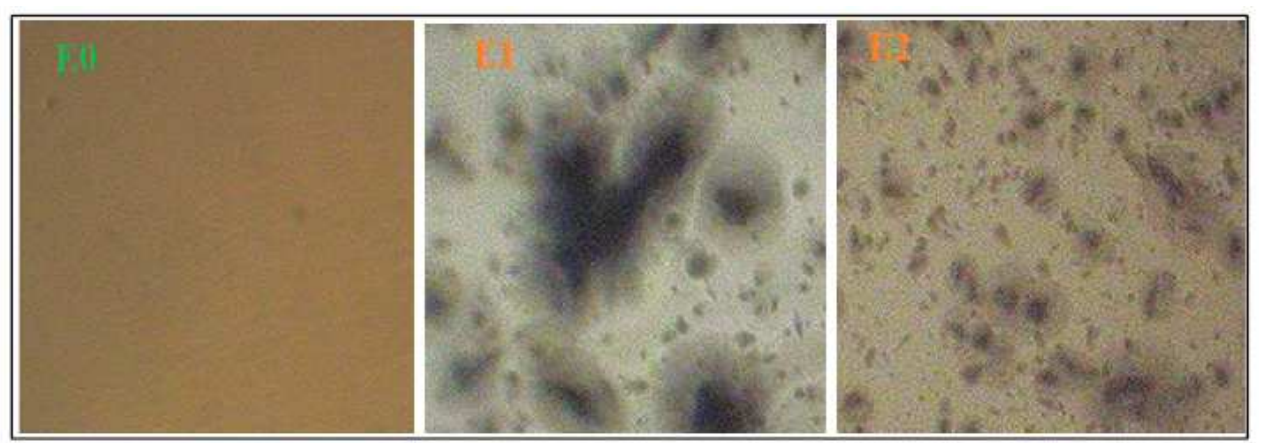

Figure 11. Photos of the standard, crosslinked and formulated substrate surface $\left(\mathrm{E}_{0}, \mathrm{E}_{1}\right.$ and $\left.\mathrm{E}_{2}\right)$.

The surface morphology of different formulations $\left(\mathrm{E}_{0}, \mathrm{E}_{1}\right.$ and $\left.\mathrm{E}_{2}\right)$ was observed by a field emission polarizing optical microscope. The comparison of different surface morphologies based on two different $E_{1}$ (PGEPBAP/MDA) and $E_{2}$ (PGEPBAP/MDA/PN) formulations has shown that the formulation type is a key 
factor in controlling the morphology and good dispersion of the charge in the matrix onto the substrate. According to these observations of the surface morphology of the elaborated new $E_{1}$ and $E_{2}$ matrices, we have clearly shown the effective dispersion of the natural phosphate charge incorporated in the $\mathrm{E}_{2}$ matrix. This confirms the results which were, respectively, obtained by the stationary method and the transient method.

\section{Conclusion}

After the synthesis of the novel polymeric polyepoxide decafunctional architecture, decaglycidyl phosphorus penta methylene dianiline, we applied it for E24 carbon steel protection by the coating behavior process derived from the standard epoxy prepolymer formulations, methylene dianiline and natural phosphate used as a load. The electrochemical studies results, namely, the potentiodynamic polarization curves, and the electrochemical impedance spectroscopy, are quite in reasonable agreement, as the addition of natural phosphate to the formulated $\mathrm{E}_{2}$ matrix (DGPMDAP/MDA/PN) has a very good protection effect. The potentiodynamic polarization that reflects the performed method initially shows the current density diminution in the cathodic and anodic domains. However, the electrochemical impedance spectroscopy reflecting the transient method shows the best results for the coating by the charged matrix $\left(E_{2}\right)$, followed by the retuned matrix $\left(E_{1}\right)$, and the control. The phase angle and Bode diagrams confirm the electrochemical impedance spectroscopy results, as well as the formulated $\mathrm{E}_{2}$ matrix morphological study using the polarizing optical microscope. In prospect, we will carry out the theoretical study with the DFT method. This will be done to confirm the adhesion sites on the metal support.

\section{References}

1. Fetouaki S, Toufik M, Meghraoui H, et al. Phys Chem New J. 2006;27:131140.

2. Hsissou R, Elharfi A. Int J ChemTech Res. 2017;10; 891-902.

3. Hsissou R, El Rhayam Y, Elharfi A. Int J Innov Appl Stud. 2014;7;674682.

4. Hsissou R, Dagdag O, Elharfi A. Mor J Chem. 2015;3:791-797.

5. Hsissou R, Elharfi A. Mor J Chem. 2016;4;315-323.

6. Hsissou R, Bekhta A, Elharfi A. J Mater Environ Sci. 2017;8;603-610.

7. Grich M, Meghraoui H, Ziraoui R, et al. Ann Chim Sci Mat. 2011;36;1-10.

8. Hsissou R, El Bouchti M, Elharfi A. J Mater Environ Sci. 2017;8;43494361.

9. Gohardani O, Williamson DM, Hammond DW. J Wear. 2012;294295;336-346.

10. Dagdag O, El Gouri M, Galai M, et al. Der Pharma Chem. 2015;7;114-122.

11. Hsissou R, Benassaoui H, Benhiba F, et al. J Chem Technol Metall. 2017;52;431-438.

12. Cantor A, Bushman J, Glodoski M, et al. Mater. Perf. 2006;45;38-41. 
13. Antonijevic MM, Petrovic MB. Int J Electrochem Sci., 2008;3;1-28.

14. Petitjean J, Aeiyach S, Lacroix JC, et al. J Electroanal Chem. 1999;478;92100.

15. Panah NB, Danaee I. Prog Org Coat. 2010;68;214-218.

16. Ferreira CA, Aeiyach S, Delamar $\mathrm{M}$, et al. Chem Interf Electrochem. 1990;284;351-369.

17. Hsissou R, Bekhta A, El Hilal B, et al. Int J Sci Eng Res. 2017;8;1181-1188.

18. Hsissou R, Rafik M, Hegazi SE, et al. Arab J Chem Env Res. 2016;3;35-50.

19. Zubielewicz M, Gnot W. Prog Org Coatings. 2004;49;358-371.

20. Rossenbeck B, Ebbinghaus P, Stratmann M, et al. Corros Sci. 2006;48;3703

21. Liu S, Zhong Y, Jiang R, et al. Corros Sci. 2011;53;746.

22. Kumar SA, Balakrishnan T, Alagar M, et al. Prog Org Coat. 2006;55;207217.

23. Benali O, Larabi L, Traisnel M, et al. Appl Surf Sci. 2007;253;6130-6139.

24. Guillaumin V, Landolt D. Corros Sci. 2002;44;179. 